\title{
Survey of the Patterns of Nest Box Use Among Squirrels (Sciuridae) in Managed Forest Stands in Clinton County, New York
}

\author{
V. Alex Sotola* and Danielle E. Garneau
}

State University of New York at Plattsburgh, 101 Broad Street, Plattsburg, New York, USA

\begin{abstract}
Artificial habitat enhancements are important forest structural components that can increase the survival of squirrels (Sciuridae) and thus warrant study. Investigations of squirrel nest box usage can provide useful demographic and community information such as occupancy rates, litter size, habitat preference, species richness and abundance estimates. This artificial nest box study investigated the nesting patterns of squirrels from late winter through early fall 2011 in managed forest stands in Clinton County, New York. Squirrels are sensitive to forest disturbance, hence we compared sites of varying silvicultural activity (e.g., managed for production of timber or maple syrup versus an undisturbed reference stand). A total of 48 nest boxes were constructed and monitored across three separate sites (e.g., reference, logged, and sugaring). Prior research suggested that occupancy may be a function of nest box height $(\sim 3.5 \mathrm{~m}$ and $\sim 5 \mathrm{~m})$ and site-specific tree cavity/snags/drey abundance, thus height preference and alternative nesting options were monitored in the survey and analyzed to report detection probability and occupancy estimates in Program Presence. Visual confirmation of northern flying squirrels (Glaucomys sabrinus Shaw) was made in $81 \%, 44 \%$, and $13 \%$ of the nest boxes in the reference, logged, and sugar site, respectively. Approximately $79 \%$ of the nest boxes showed evidence of wildlife visitation (e.g., scat, crushed seeds, or nesting material). Additionally, $87 \%$ of the high boxes $(5 \mathrm{~m})$ versus $71 \%$ of the low boxes $(3.5 \mathrm{~m})$ were utilized, and $17 \%$ of all occupancies contained multiple individuals. This survey provides additional multi-season occupancy data for an elusive mammal species under managed habitat regimes. We recommend that management plans include a wildlife habitat component that maintains snag trees and live cavity-trees in forest stands. When appropriate, stand management plans could also include installing habitat enhancement structures such as artificial nest boxes for squirrels.
\end{abstract}

Keywords: Flying squirrel, management, nest boxes, nesting patterns, Red Squirrel, Squirrel.

\section{INTRODUCTION}

The degradation and loss of natural resources are some of the long-standing environmental concerns. Anthropogenic disturbances often have detrimental consequences for wildlife habitat which manifest in reduced nesting opportunities, and in extreme cases, extirpation (Wijesinghe and Brooke, 2005; Herbers and Klenner, 2007). Silvicultural methods such as shelterwood cutting or clear cutting may benefit wildlife species (e.g., yellow-pine chipmunk (Neotamias amoenus)), by releasing understory vegetation and favoring regeneration of early successional species (Herbers and Klenner, 2007). However, for tree squirrels such as northern flying (Glaucomys sabrinus Shaw), red (Tamiasciurus hudsonicus Erxleben), and gray (Sciurus carolinensis) squirrels, trees support their dreys (Trudeau et al., 2011) and are required for nesting cavities (Fokidis and Risch, 2005; Merrick et al., 2007; Lindenmayer et al., 2009). In scenarios where clearcutting has occurred, or there is a reduction in preferred nesting trees, tree squirrels and cavitydependent birds have declined in abundance (McComb and

*Address correspondence to this author at the State University of New York at Plattsburgh, 101 Broad Street, Plattsburg, New York, USA;

Tel: 518-269-8964; E-mail: vasotola@gmail.com
Noble, 1981; Taulman et al., 1998; Ramos-Lara and Cervantes, 2007). Habitat management has often been employed to enhance thinned forests by adding nest boxes to accommodate displaced species. Lindenmayer et al. (2009) reported a significant increase in the abundance of cavitydependent species (e.g., bird and squirrel species) by installing nest boxes in previously logged forests.

Flying and red squirrels are both members of the family Sciuridae; however, they differ in habitat preference, behavior, and distribution. Red squirrels are more generalist in terms of requirements (e.g., food, shelter, mates), as compared to the narrow niche of northern flying squirrels (Whitaker and Hamilton, 1998). Behaviorally, northern flying squirrels nest in tree cavities, while red squirrels prefer snags and construct dreys out of bark, twigs, and leaves (Patterson and Malcolm, 2010). Niche differentiation also results from resource partitioning among tree squirrels. Rosenberg and Anthony (1991) noted that flying squirrels prefer to feed on fungi and lichens growing on spruce (Picea spp.) trees, whereas Whitaker and Hamilton (1998) noted that red squirrels prefer hard mast such as oak (Quercus spp.) acorns, hickory (Carya spp.) and American beech (Fagus grandifolia) nuts.

Niche partitioning among species that are functionally redundant is one means of reducing competition. Northern 
flying squirrels are nocturnal and home ranges are typically 5 - 27ha, but will defend a territory on average 3.6ha in size and average one litter per year starting in late March (Whitaker and Hamilton, 1998; Taulman and Smith, 2004). Contrastingly, red squirrels have a much smaller range, 1.3 1.5 ha, but will aggressively defend a 0.2 - 1.2 ha territory. Behaviorally, they are diurnal and exhibit two breeding seasons from March - May and July - September (Klugh, 1927; Whitaker and Hamilton, 1998). Competition between the two species results from habitat overlap and arboreal lifestyles, with demands for tree cavities and nesting materials. Red squirrels are prevalent in both deciduous and coniferous forests, usually preferring the tallest living trees. Additionally, they are sensitive to habitat alteration such as wildfires or logging (Russel et al., 2010), which may diminish prime nesting habitat for squirrels.

The implementation of artificial nest boxes in a habitat of the proper size and height, can positively affect a squirrel population. Ramos-Lara and Cervantes (2007) found that sturdy nest boxes can buffer squirrels from wind, rain and cold temperatures. Most animals use some sort of shelter for protection against adverse weather conditions, predators, competitors, and diseases. Further research is needed to help determine the influence of predation. Because predation is one of the main threats that animals face during their daily routines, and nest boxes have been found to both reduce predation (Ramos-Lara and Cervantes, 2007; Lindenmayer et al., 2009) or minimally affect predation risk (Brady et al., 2000; Merrick et al., 2007; Trudeau et al., 2011), it would be useful to undertake more research on this subject. The more permanent nature of nest boxes, relative to dreys, may place their occupants at a greater risk of predation from mammalian predators (Shuttleworth, 1999) because predators target predictable sources of prey. However, with sturdy construction, nest boxes can withstand predator attack, whereas weaker dreys may be more susceptible. Fokidis and Risch (2005) altered their nest box design, by reducing the diameter of the nest box entry hole, in an attempt to limit predation of inhabitants.

We predicted that the dominant species inhabiting nest boxes at managed and reference sites would be red squirrels with occasional visits by other tree squirrels (e.g., flying squirrels and gray squirrels). We also predicted that sites with a greater cavity, drey, or snag abundance would limit squirrel nest box occupancy. Additional predictions were made that managed sites (e.g., logged and sugar) would possess fewer natural nesting opportunities and therefore would experience higher nest box occupancy rates. Lastly, we predicted squirrel preference would be for higher boxes, which would provide more protective foliage cover. Numerous wildlife species are ecological indicators of forest health and are therefore important for conservation. Smith et al. (2011) and Wheatley et al. (2005) found that flying squirrels are keystone indicators for mature forests. In particular, flying squirrels are sensitive to forest management and their presence may be an indicator of high-quality forest (Taulman et al., 1998). For many reasons, wildlife ecologists need to understand how anthropogenic disturbances affect members of the Sciuridae family.

\section{METHODS}

\section{Site Description}

Study sites were located in Clinton County, the northeastern-most county in New York on property owned by the William H. Miner Agricultural Research Institute in the town of Chazy, New York. The reference site $\left(19,397.3 \mathrm{~m}^{2}\right)$ is a northern hardwood forest that had not been logged in $>15$ years and experienced minimal anthropogenic disturbance. The sugar site $\left(26,450.1 \mathrm{~m}^{2}\right)$ was comprised of mixed forest (e.g., sugar maple (Acer saccharum), white pine (Pinus strobes), and eastern hemlock (Tsuga canadensis) bisected by plastic tubing used for sap lines. Foot, ATV, and snowmobile traffic was common in this area due to tap and sap line maintenance. There was sparse ground cover and lesser tree densities, as compared to the reference site. The logged forest site $\left(43,123.6 \mathrm{~m}^{2}\right)$ was harvested within the past 2-3 years (pers. com., Herbert Boyce, Northeast Forest Consultants). The logging trails were easily recognizable, and tree regeneration was evident. White pine trees were not removed and their canopy dominance was high. Site area was determined using minimum bounding geometry (convex hull) based on nest box arrangement in ArcMap vers. 10.1 (ESRI, Redlands, CA).

\section{Nest Box Construction}

Nest boxes $(n=48)$ were constructed using $3 / 4$ in pressuretreated plywood $(56 \mathrm{~cm} \times 23.5 \mathrm{~cm} \times 19.7 \mathrm{~cm})$ and were modified with a side entry hole ( $4 \mathrm{~cm}$ diameter). The entry hole modification was made to prevent entry of non-target species (e.g., birds or other small mammals). Nest boxes were fastened to trees with the entry hole facing a southerly direction (Ramos-Lara and Cervantes, 2007). Nest boxes were filled, approximately 2 in, with sheep's wool bedding for use during the winter (Macomb and Noble, 1981).

\section{Nest Box Installation}

Sites were selected for nest box installation and field sampling such that 16 boxes were erected per site, equally partitioned across four stands (four boxes per stand) (Fokidis and Risch, 2005; Brady et al., 2000; Shuttleworth, 1999). At each site, two out of the four stands were fastened to a conifer at approximately $3.5 \mathrm{~m}$ and the other two stands at $5 \mathrm{~m}$ high, such that half $(\mathrm{n}=24)$ of the nest boxes were located high $(5 \mathrm{~m})$ and half low $(3.5 \mathrm{~m})$ (Risch and Brady, 1996). The nest boxes were located at least $45 \mathrm{~m}$ away from roads and $20 \mathrm{~m}$ apart from other boxes (Lindenmayer et al., 2009). Sites were marked using a Garmin (60CSx) global positioning system (GPS) unit. A geographic information systems (GIS) map project (ArcMap vers. 9.2) was developed to mark site-specific nest box locations.

\section{Nest Box Surveys}

This seasonal nest box survey commenced in early February 2011 and ceased in November 2011. From February until May 2011, weekly nest box occupancy was assessed by means of visual inspection from a ladder. During 
Table 1. Site- and height-specific detection probabilities calculated using program presence from each particular site.

\begin{tabular}{|c|c|c|}
\hline Variable & $\begin{array}{c}\text { Detection } \\
\text { Probability }\end{array}$ & $\begin{array}{c}\text { Occupancy } \\
\text { Estimate }\end{array}$ \\
\hline \hline Reference Site & 0.23 & 0.81 \\
\hline Logged Site & 0.06 & 0.44 \\
\hline Sugar Site & 0.007 & 0.13 \\
\hline High Boxes $(5 \mathrm{~m})$ & 0.20 & 0.63 \\
\hline Low Boxes (3.5m) & 0.12 & 0.29 \\
\hline
\end{tabular}

Table 2. Site-specific abundance of snags, dreys, and cavities and percent boxes occupied $(\mathrm{n}=16 /$ site $)$.

\begin{tabular}{|c|c|c|c|c|}
\hline Site & Snags & Dreys & Cavities & \% Boxes Occupied \\
\hline \hline Reference & 68 & 2 & 3 & 81 \\
\hline Logged & 30 & 0 & 9 & 44 \\
\hline Sugar & 52 & 0 & 9 & 13 \\
\hline
\end{tabular}

the summer months (June - August, 2011) with lesser manpower, nest boxes were checked every other week. Summer visits consisted of a comparison of the reference site (constant) paired with a managed site (alternating between sugar and logged). Total visit counts for the reference site totaled 20 checks, with 18 checks at each experimental site. Squirrel occupancy was assumed and noted if animals and/or signs of their presence (e.g., nut husks, scat, nesting materials) were visible. The presence of sign was noted only for the first observation, so as to reduce error associated with redundant counts, although every time a squirrel was observed it was noted in that particular box.

Infrared motion cameras (Stealth Camera I540IR), one per site, were erected at $3.5 \mathrm{~m}$ and $5 \mathrm{~m}$ from base of a tree, oriented directly across the nest box, to serve as a secondary occupancy and predator monitoring method (Gommper et al., 2006). Commencing in September 2011, a camera (iPhone 4) was attached to the end of a telescoping pole. This camera was inserted inside the nest box through the entry hole for approximately $30 \mathrm{sec}$ to record video of inhabitants. Prior to filming, the box was lightly tapped to awake or arouse any animal inside the box so they would become curious and poke their heads out of the sheep's wool; however, it was noted that the squirrels commonly slept atop the wool, so not observing the squirrels was not a major issue.

\section{Nest Site Scores}

The abundance of standing dead trees, dreys, and tree cavities was recorded once per stand by surveying the area around each stand in a $40 \mathrm{~m}^{2}$ area (Lindenmeyer et al., 2009). The number of snags, dreys, and cavities were summed to produce a composite score, which was later correlated with nest box occupancy rates (Table 2).

\section{Statistical Analysis}

To model occupancy, we used Program Presence (USGS and Darryl MacKenzie) to determine the site- and heightspecific detection probabilities and occupancy estimates; direct observations of squirrels and sign (e.g., scat) were not used in the model. To determine the significance of occupancy versus height, as well as site, we ran a one-way ANOVA. We created graphs of site-specific percent occupancy versus time (Julian Date) and site score (dreys + snags + cavities) versus the number of occupied nest boxes. Site - and height-specific percent occupancy was also calculated.

\section{RESULTS}

Of the species that inhabited our nest boxes, 99\% $(\mathrm{n}=$ $72)$ and $1 \%(n=1)$ were flying and red squirrels, respectively. The first nest box occupancy events occurred two weeks, seven months, and eight months post-erection, at the reference, logged, and sugar sites, respectively. Overall, $82 \%, 15 \%$, and $3 \%$ of the nest box occupancies occurred at the control, logged, and sugar sites, respectively; occupancy as a function of site and height was significant $(F(2,6)=$ $7.47, p=0.024$ ) (Fig. 1). There were no seasonal patterns of nest box occupancy, although squirrels did not start colonizing boxes in the logged and sugar site until fall (Fig. 1). Detection probability and estimated occupancy calculated with Program Presence were highest for the reference site ( 0.23 and 0.81 , respectively) and for the high nest boxes ( 0.20 and 0.63 , respectively), as compared to managed sites and low nest boxes (Table 1).

At each site, there were more occurrences of observed signs, as compared to direct squirrel observations. This occupancy trend was most noticeable at the sugar site, where 

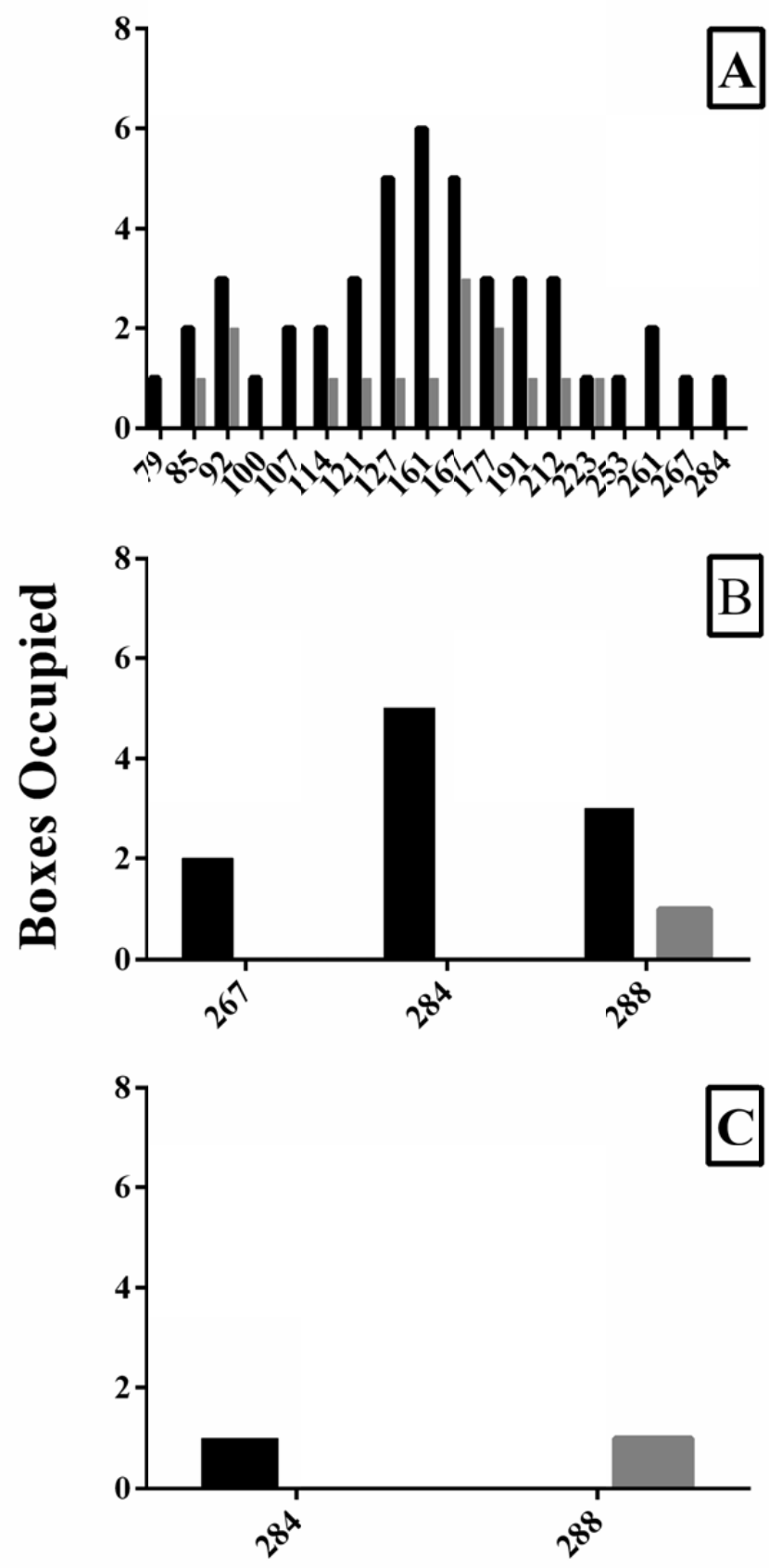

Julian Date

Fig. (1). Reference (A), logged (B), and sugar (C) site occupancy rates. Bars fall on the specific Julian day on which occupancies occurred. Box height represented by high (black) and low (gray).

only two boxes were directly occupied, as compared to 12 of the 16 boxes containing sign alone (Fig. 2). It was found that $63 \%$ of the high, as compared to $29 \%$ of the low boxes, were occupied by squirrels (Fig. 3). Using indirect sign evidence (e.g., scat, nesting material, food), $88 \%$ of the high and $71 \%$ of the low nest boxes had sign present (Fig. 3). Only one image of a flying squirrel was captured, and no predators were ever observed with the stealth camera.
There was a weak positive correlation between the composite score and the number of occupied nest boxes $\left(\mathrm{r}^{2}=\right.$ 0.1187) (Table 2, Fig. 4). Dreys were uncommon in all 3 sites, as were cavities which were three times more common in the sugar site, but were still rare in the survey. The reference site contained 2.27 and 1.73 times more snags than the managed sugar and logged sites, respectively. However, $81 \%, 44 \%$, and $13 \%$ of the 16 boxes occupied were in reference, logged, and sugar sites, respectively. 


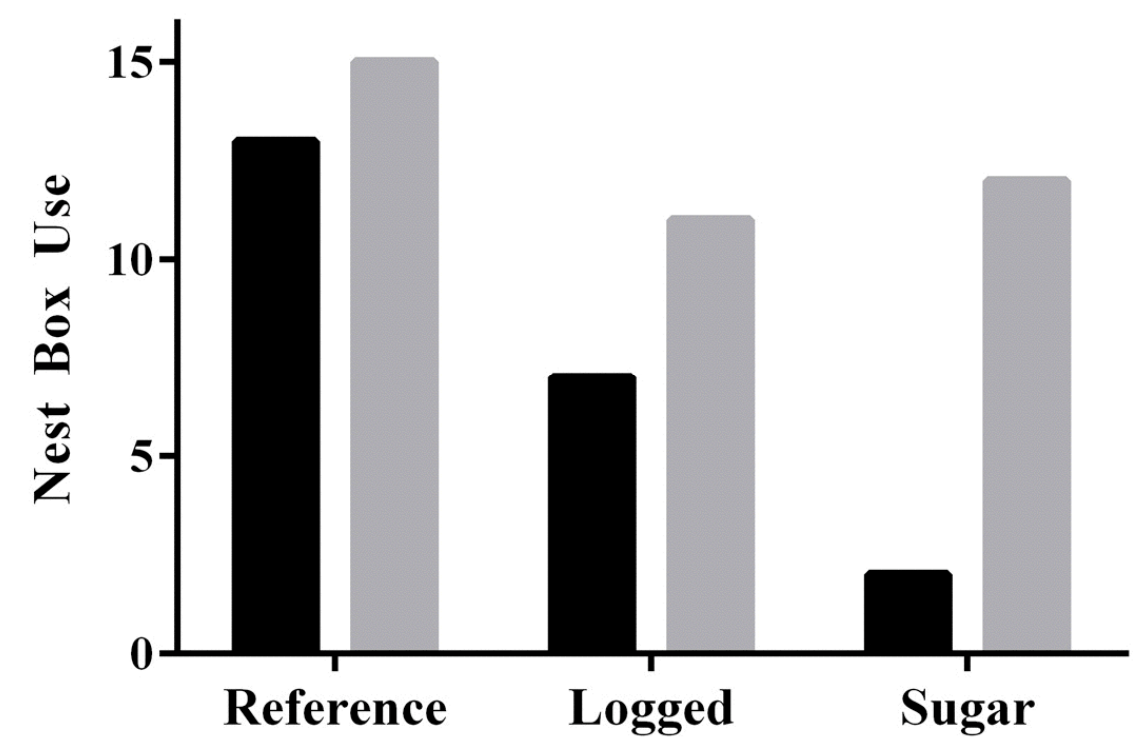

Fig. (2). Site-specific nest box utilization as a function of direct observation (black) and sign (gray).

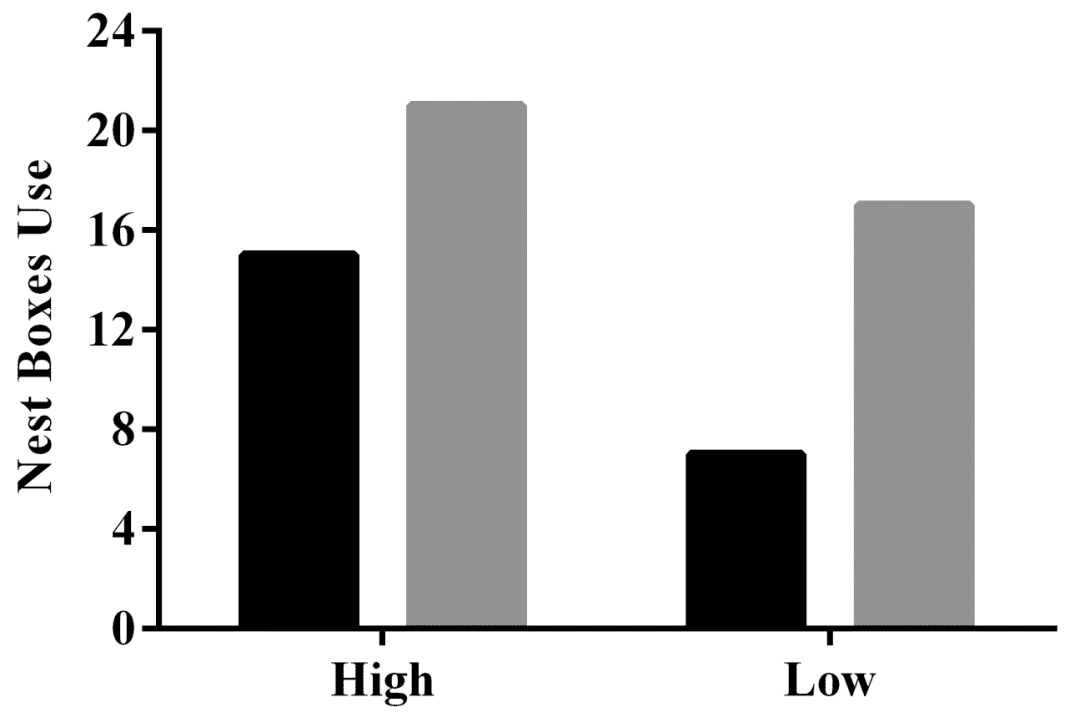

Fig. (3). Height-specific nest box utilization as a function of direct observation (black) and sign (gray), where high and low are at $5 \mathrm{~m}$ and $3.5 \mathrm{~m}$, respectively.

\section{DISCUSSION}

Understanding species' nesting patterns and requirements, such as those of tree squirrels, can assist forest managers when planning harvest regimes. We predicted that the dominant species inhabiting nest boxes would be red squirrels, with rare occupancy by other tree squirrels; however, the majority (99\%) of occupants was flying squirrels. It was predicted that red squirrels would be the primary inhabitants of artificial nest boxes, as they are regionally common. However, only one instance of red squirrel nest box occupancy, a communal group of four, was recorded at the reference site in a high nest box. A possible explanation for the rare observations of red squirrels is due to their diurnal habits (Merritt et al., 2001). As such, the timing of nest box surveys did not coincide with their daily activities, which created a reporting bias favoring flying squirrels.
Thinning and other silvicultural management practices have been known to alter the distribution and abundance of small mammals, and adversely affect their survival and reproduction (Wood et al., 2007). The majority (81\%) of occupied nest boxes occurred in the reference site, which suggests that flying squirrels are sensitive to logging and natural disturbances (Patterson and Malcolm, 2010). Sitespecific occupancy rates were found to be significantly different, suggesting sensitivity to silvicultural practices among the flying squirrels. In particular, nest boxes in managed sites should have higher occupancy rates due to fewer natural nesting opportunities. However, this prediction was not supported in this case, as the reference site had the highest composite score (abundance of natural nests), as well as the highest rate of nest box occupancy.

Nest box height is often a concern for managers augmenting forest structure for wildlife (Risch and Brady, 1996). We predicted that higher nest boxes would experience 


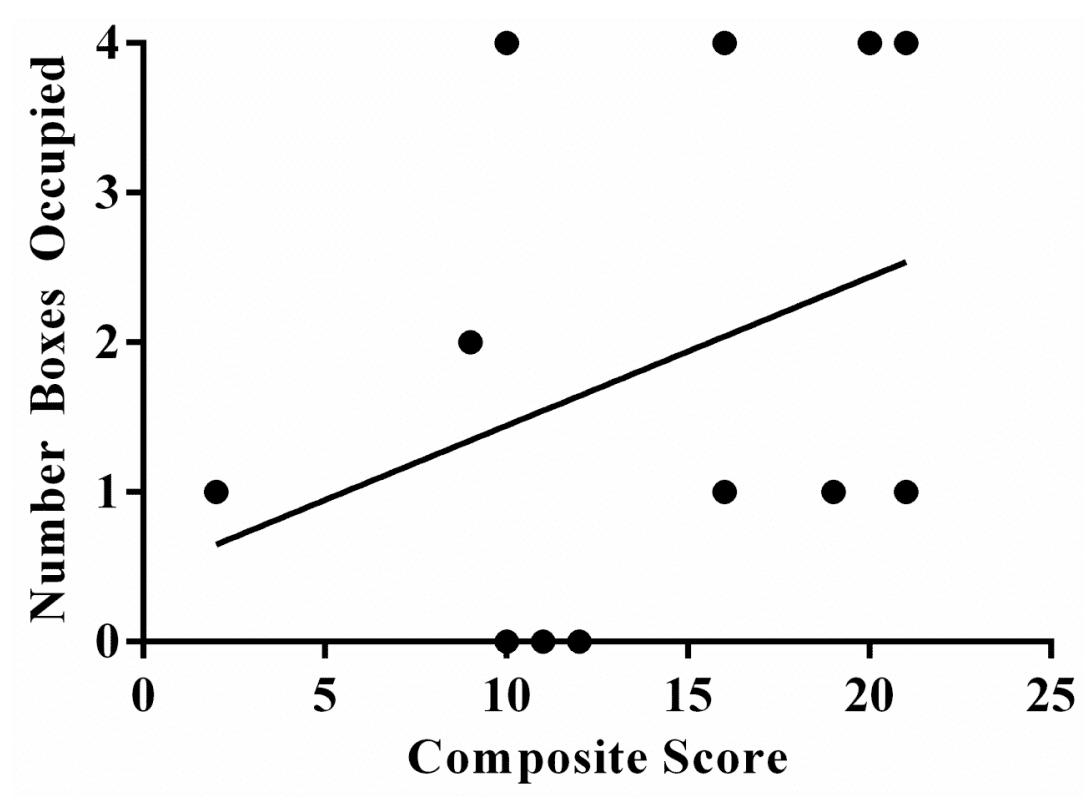

Fig. (4). Correlation between composite score (e.g., dreys, snags, and natural cavities) and next box occupancy.

greater occupancy rates than those lower ones. Our data support this prediction with utilization of $63 \%$ of the high versus $29 \%$ of the low boxes. The model from Program Presence also supports this claim with a 0.20 detection probability and a 0.63 occupancy estimate of the high boxes versus a 0.12 detection probability and a 0.29 occupancy estimate for low boxes. Flying squirrels may prefer higher boxes because higher canopy height might enhance gliding time and provide greater protective cover (Pyare and Longland, 2002).

It was expected that there would be time lags in first nest box occupancy, as wildlife is known to be wary of foreign structures. The first instance of nest box occupancy occurred two weeks after box installation, which is similar to the occupancy rates Goertz et al. (1975) observed with their first nesting squirrels. Approximately $15 \%$ and $3 \%$ of nest box occupancies occurred at the logged and sugar maple managed sites at 7 and 8 months following nest box installation, respectively. This occupancy time lag might result from an overall lesser density of flying squirrels in selectively harvested stands and maintenance of sugar lines. Flaherty et al. (2008) found that flying squirrels have an increased home-range size $(100-150 \mathrm{~m})$ in managed areas (e.g., logged, sugar) as compared to unmanaged old-growth $(25-50 \mathrm{~m})$ stands. In addition to having larger home ranges, Carey (2002) found that there were fewer flying squirrels ( 0.5 individuals/ ha) in managed sites, as compared to those unmanaged. This finding might also explain the latency in first occupancy and lesser frequency of occupancy observed in our study. Anthropogenic disturbances, such as thinning for timber or non-timber products (maple sugar), are known to detrimentally affect flying squirrels. Loss of habitat and resources was noted in earlier studies where logging practices occurred (Taulman and Smith, 2004). Additionally, this range expansion could explain the delay of occupancy because if their home range is larger, time spent in surveyed areas might be lesser.

Monitoring wildlife directly can be difficult, as many species are nocturnal and secretive. As a result, wildlife sign (e.g., scat, hair) can be used as an index of animal presence/absence. Over the course of the survey, regardless of site, we noted more instances of animal sign than confirmed squirrel observations. At the reference site, sign versus direct observation was noted in $94 \%$ and $81 \%$ of monitoring events. Among managed sites, $69 \%$ and $75 \%$ of the nest boxes contained sign in the logged and sugar maple site, respectively. This is in contrast to the $44 \%$ and $13 \%$ observed occupancies in those same logged and sugar maple sites. Implications for these findings provide support that squirrels may use these boxes as temporary homes, refuges, or food caches. Additionally, diurnal red squirrels may be using the boxes at night, while evading daytime survey inclusion while actively foraging.

Forest structure, resulting in vertical stratification, may facilitate coexistence among members of the tree squirrel guild. Risch and Brady (1996) found that the majority $(79.5 \%)$ of flying squirrel nest box occupancies occurred above $4.5 \mathrm{~m}$ canopy height, whereas only $20.5 \%$ occurred at the $2 \mathrm{~m}$ height. Trudeau et al. (2011) found that $36 \%$ versus $39 \%$ of squirrels preferred ground nests to dreys. We found that both animal sign and occupancy were more abundant in the upper canopy $(5 \mathrm{~m})$ nest boxes. Specifically, sign presence was noted in $55 \%$ of high versus $45 \%$ of low nest boxes, albeit the trend was not statistically significant. Similarly insignificant site-specific trends were noted for squirrel occupancy in $77 \%$ high versus $23 \%$ low nest boxes, suggesting preference for higher canopy refuges at all sites.

Pyare and Longland (2002) found that there are two important factors affecting the nest site selection among tree squirrels: 1) mean distance to the nearest neighbor tree, and 2) mean percentage of canopy cover. These same researchers reported that flying squirrels were capable of gliding more than $50 \mathrm{~m}$ from the higher canopy, in part because shorter gliding distances to lessen predation risk were preferable. Since squirrels were observed less often than presence of sign in low boxes, squirrels could have used the low boxes as refugia or as a food cache. Merrick et al. (2007) provide support for this finding, as they noted that in times of 
resource scarcity, squirrels use nests and cavities as food caches. We did not survey food availability, but given the abundance of animal sign at all sites, it can be assumed that caching was commonplace.

Animal aggregation is a known behavior which provides thermoregulatory benefits among winter-active wildlife (West and Dublin, 1984). In our study, approximately $17 \%$ of all occupancies consisted of multiple individuals. Of those nest box aggregations, the majority (92\%) of observations occurred in high versus $8 \%$ low nest boxes. Our results suggest that at times, squirrels are communal during winter months, as was previously documented (Merritt et al., 2001; Dolan and Carter, 1977; Wells-Gosling and Heany, 1984). These researchers observed that during times of food scarcity or cold temperatures, as in winter months, squirrels become communal and form social groups to assist with thermoregulation. Additionally, Layne and Raymond (1994) found that squirrels exhibit site fidelity and remain with associates over prolonged periods. Albeit the difference was insignificant, nest box occupancy varied by season, such that $21 \%, 25 \%$ and $55 \%$ occurred in fall, summer, and spring, respectively. Most northeastern tree squirrels find need for shelter during the breeding period, in late winter and early spring (Whitaker and Hamilton, 1998).

As noted by the score-occupancy relationship, in addition to the reference site having the greatest observed occupancies, flying squirrels and potentially other arboreal mammals appear to prefer artificial nest boxes to naturally occurring nests. These artificial structures are known to provide benefits for squirrels in both managed and reference forests for multiple reasons (e.g., protection, potential resource cache, and thermoregulation) that might surpass those provided by natural structures (Shuttleworth, 1999). It takes time for the squirrels to locate nest boxes, which might result in occupancy delays at each site, but once located they are often utilized continually. Ransome et al. (2004) discovered that for nest selection, squirrels were primarily food and predator-restricted. Their research did not suggest that squirrels were habitat-limited, due to lack of nesting refugia, perhaps as a function of high site quality. If there is adequate food, even though habitat lacks in natural cavities, then nest boxes are useful structures for enhancing tree squirrel survival. Further research should include long-term and night monitoring of nest boxes to assess variation and diel occupancy patterns. Additionally, non-invasive molecular techniques of sign (i.e., hair, nest box bedding) should be used to confirm occupants as red squirrels or either northern and/or southern flying squirrels. Finally, longitudinal forest community surveys should be performed to capture forest composition and tree distribution, in addition to predator surveys.

\section{CONFLICT OF INTEREST}

The authors confirm that this article content has no conflicts of interest.

\section{ACKNOWLEDGMENTS}

A very special thanks goes to Jason Leewe for assisting with nest box deployment and monitoring during the study.
SUNY Plattsburgh professors Drs. Kenneth Adams and Rachel Schultz are also thanked for manuscript review and statistical analysis support. Additional thanks are paid to George Maynard, Will Goumas, Timothy Shearman, Siobhan Levere, Alejandro Reyes, Erin Hayes-Pontius, and Thomas Maynard for assistance in nest box monitoring. Logistical support is appreciated and warrants acknowledgements to Steve Fessette, Steve Kramer, Kirk Beattie, and Eileen Allen. Funding for this research was provided by the Center for Earth and Environmental Science at SUNY Plattsburgh and the W.H. Miner Agricultural Institute. Additional thanks goes to the W.H. Miner Agricultural Institute for land access, remote cameras, and construction of nest boxes (Steve Fessette).

\section{REFERENCES}

Brady, MJ, Risch, TS \& Dobson, FS (2000) Availability of nest sites does not limit population size of southern flying squirrels. Canadian Journal of Zoology, 78(7), 1144-9.

Carey, AB (2002) Response of northern flying squirrels to supplementary dens. Wildlife Society Bulletin, 30(2), 547-56.

Dolan, PG \& Carter, DC (1977) Glaucomys volans. Mammalian Species, $78,1-6$.

Elzinga, CL, Salzer, DW, Willoughby, JW \& Gibbs, JP (2001). Monitoring Plant and Animal Populations, Blackwell Science, Inc, Malden, MA.

Flaherty, EA, Smith, WP \& Ben-David, M (2008) Experimental trials of the northern flying squirrel (Glaucomys sabrinus) traversing managed rainforest landscapes: perceptual range and fine-scale movements. Canadian Journal of Zoology, 86, 1050-58.

Fokidis, HB \& Reisch, TS (2005) The use of nest boxes to sample arboreal vertebrates. Southeastern Naturalist, 4(3), 447-58.

Goertz, JW, Dawson, RM \& Mowbray, EE (1975) Response to Nest Boxes and Reproduction by Glaucomys volans in Northern Louisiana. Journal of Mammalogy, 56(4), 933-39.

Gompper, ME, Kays, RW, Ray, JC, Lapoint, SD, Bogan, DA \& Cryan, JR (2006) Comparison of Noninvasive Techniques to Survey Carnivore Communities in Northeastern North America. Wildlife Society Bulletin, 34(4), 1142-51

Herbers, J \& Klenner, W (2007) Effects of logging pattern and intensity on squirrel demography. The Journal of Wildlife Management, 71(8), 2655-63.

Klugh, AB (1927) Ecology of the red squirrel. Journal of Mammalogy, 8(1), $1-32$

Layne, JN \& Raymond, MA (1994) communal nesting of southern flying squirrels in florida. Journal of Mammalogy, 75(1), 110-20.

Lindenmayer, DB, Welsh, A, Donnelly, C, Crane, M, Michael, D, Macgregor, C, McBurney, L, Montague-Drake, R \& Gibbons, P (2009) Are nest boxes a viable alternative source of cavities for hollow-dependent animals? Long-term Monitoring of Next Box Occupancy, Pest Use and Attrition. Biological Conservation, 142(1), 33-42.

McComb, WC \& Noble, RE (1981) Nest-Box and natural cavity use in three mid-south forest habitats. The Journal of Wildlife Management, 45 (1), 93-101.

Merritt, JF, Zegers, DA \& Rose, LR (2001) Seasonal thermogenesis of southern flying squirrels (Glaucomys volans). Journal of Mammalogy, 82(1), 51-64.

Merrick, MJ, Bertelsen, SR \& Koprowski, JL (2007) characteristics of mount graham red squirrel nest sites in a mixed conifer forest. The Journal of Wildlife Management, 71(6), 1958-63.

Patterson, JEH \& Malcolm, JR (2010) Landscape structure and local habitat characteristics as correlates of Glaucomys sabrinus and Tamiasciurus hudsonicus occurrence. Journal of Mammalogy, 91, $642-53$.

Pyare, S \& Longland, WS (2002) Interrelationships among northern flying squirrels, truffles, and microhabitat structure in Sierra Nevada oldgrowth habitat. Canadian Journal of Forest Research, 32, 1016-24.

Ramos-Lara, N \& Cervantes, FA (2007) nest-site selection by the mexican red-bellied squirrel (sciurus aureogaster) in michoacan, Mexico. Journal of Mammalogy, 88(2), 495-501. 
Ransome, DB, Lindgren, PMF, Sullivan, DS \& Sullivan, TP (2004) Longterm responses of ecosystem components to stand thinning in young lodgepole pine forest. I. Population dynamics of northern flying squirrels and red squirrels. Forest Ecology and Management, 202, 355-67.

Risch, TS \& Brady, MJ (1996) Trap Height and Capture Success of Arboreal Small Mammals: evidence from southern flying squirrels (Glaucomys volans). The American Midland Naturalist, 136 (2), 346-51.

Russel, RE, Lehmkuhl, JF, Buckland, ST \& Saab, VA (2010) Short-Term responses of red squirrels to prescribed burning in the interior pacific northwest, USA. Journal of Wildlife Management, 74(1), 12-17.

Shuttleworth, CM (1999) The Use of Next Boxes by the Red Squirrel (Sciurus vulgaris) in a Coniferous Habitat. Mammal Review, 29 (1), 61-66.

Smith, WP, Person, DK \& Pyare, S (2011) Source-sinks, metapopulations, and forest reserves: conserving northern flying squirrels in the temperate rainforests of Southeast Alaska In Liu, J, Hull, V, Morzillo, AT, \& Wiens, J, (Ed) Sources, sinks, and sustainability across landscapes. Cambridge University Press, Cambridge, United Kingdom.

Taulman, JF \& Smith, KG (2004) home range and habitat selection of southern flying squirrels in fragmented forests. Mammalian Biology, 69(1), 11-27.

Taulman, JF, Smith, KG \& Thill, RE (1998) demographic and behavioral responses of southern flying squirrels to experimental logging in arkansas. Ecological Applications, 8(4), 1144-55.
Trudeau, C, Imbeau, L, Drapeau, P \& Mazerolle, MJ (2011) site occupancy and cavity use by the northern flying squirrel in the boreal forest. Journal of Wildlife Management, 75(7), 1646-56.

Weigl, PD (1974) Study of the northern flying squirrel, Glaucomys sabrinus, by temperature telemetry. American Midland Naturalist, 92, 482-86.

Wells-Gosling, N and Heaney, LR (1984) Glaucomys sabrinus. Mammalian Species, 229, 1-8.

West, SD and Dublin, HT (1984) Behavioral strategies of small mammals under winter conditions: solitary or social? Winter ecology of small mammals. Special Publication, Carnegie Museum of Natural History, 10, 293-299.

Wheatley, M, Fisher, JT, Larsen, K, Litke, J \& Boutin, S (2005) Using GIS to relate small mammal abundance and landscape structure at multiple spatial extents: the northern flying squirrel in alberta, Canada. Journal of Applied Ecology, 42(3), 577-86.

Whitaker, JO \& Hamilton, WJ (1998) Mammals of the Eastern United States. 3rd Ed. Cornell University Press. Ithaca, New York.

Wijesinghe, MR \& Brooke, M de L (2005) Impact of habitat disturbance on the distribution of endemic species of small mammals and birds in a tropical rain forest in sri lanka. Journal of Tropical Ecology, 21(6), 661-68.

Wood, DJA, Drake, S, Ruston, SP, Rautenkranz, D, Lurz, PWW \& Koprowski, JL (2007) Fine-scale analysis of mount graham red squirrel habitat following disturbance. The Journal of Wildlife Management, 71(7), 2357-64.

(C) Sotola and Garneau; Licensee Bentham Open.

This is an open access article licensed under the terms of the Creative Commons Attribution Non-Commercial License (http://creativecommons.org/ licenses/by-nc/3.0/), which permits unrestricted, non-commercial use, distribution and reproduction in any medium, provided the work is properly cited. 